doi:10.5128/ERYa9.14

\title{
INTERVIEWER BEHAVIOUR DURING ORAL PROFICIENCY INTERVIEWS: A GENDER PERSPECTIVE
}

\author{
Edith Reemann, Ene Alas, Suliko Liiv
}

\begin{abstract}
The article investigates the behaviour of interviewers during the oral proficiency interview within the framework of the national examination in the English language in Estonia from the gender perspective. The research investigates whether noticeable differences can be traced in the behavioural patterns of male and female interviewers that could lead to placing the candidates in a disadvantaged position, not allowing them to display their language proficiency to the full. The study involves nine female and nine male interviewers whose interview language is subjected to content analysis. The results show an overall attempt to follow the scripted interview format envisaged for this examination, but alterations to the script prevail with both gender groups.
\end{abstract}

Keywords: interviewer, oral proficiency interview, validity, reliability, scripted interview, gender variation, standardisation

\section{Introduction}

Interviewer behaviour has been discussed in research literature from various angles: accommodation, i.e. how much interviewers adjust their speech to the person taking the test (Ross 1992, Ross, Berwick 1992, Lazarton 1996, 2002, Malvern, Richards 2002); interviewer proficiency, i.e. language proficiency combined with procedural proficiency (Morton et al. 1997, McNamara and Lumley 1997); variation in personality and communication style (Brown 2003, Luoma 2004); and rapportestablishing techniques with the candidate (Morton et al. 1997), all of which affect the assessment of candidates. For a detailed discussion of the above aspects, see Alas (2010: 25-28).

This article will concentrate on interviewer gender. O'Loughlin (2002) asserts that the female interview style is 'collaborative, symmetrical, co-operative, and

* The research was partly supported by the Estonian Science Foundation Grant No 9037. 
supportive whereas its male equivalent is controlling, asymmetrical, uncooperative, and unsupportive' (2002: 170). Her research indicated that interviewers demonstrated a limited use of overlaps, a negligible use of interruptions and a widespread use of minimal responses in the interviews, but the use of these features did not follow any clear gender pattern. There was a high degree of variability in the use of overlaps and especially minimal responses within the different gender pairings. Most importantly, both female and male participants indicated their ability to make supportive contributions to the interviews through their use of positive overlaps and minimal responses in particular. O'Loughlin concludes that other interlocutor characteristics - interviewer training, professional orientation - probably affect the behaviour of the interviewer more than gender (2002: 190). For a detailed discussion of gender-related research see Alas (2010: 26).

Proceeding from the ambiguity of the findings of international research, and because relevant studies have not been conducted in Estonia, a research hypothesis was posed as follows: the conduct of interviewers in oral proficiency interviews (OPI) during the national examination in the English language in Estonia will display gender-related differences, which follow identifiable patterns.

\section{Method}

Interviewers involved in oral proficiency interviews for the English language national examinations in Estonia are practising teachers who are required to have undertaken standardised interviewer/assessor training. The interviewers must follow an interviewer script verbatim and adhere to the time limits for different parts of the interview. The candidates they interview are usually familiar to them.

Eighteen interviews were randomly selected from among the recordings of interviews conducted during the examination session of 2011. The principle of choosing the recordings was that the interview had to have taken place during that session, and there was to be an equal number of male and female interviewers. Although 7917 students took the English examination in the spring 2011 examination session (Põder 2011), the choice of the interviews for analysis was made from a limited pool because the recording is only made at the candidate's discretion. The interviews were transcribed and assigned letter-codes and numbers in a random order, M1 to M9 for male and F1 to F9 for female interviewers.

The speaking test of the national examination in the English language consists of an introduction (not rated), a monologue and follow-up questions (task 1), and a role-play (task 2). The overall time for a rateable sample from each candidate is estimated at between 14 and 16 minutes. The database of the eighteen recordings comprised 227 minutes and 49 seconds of interview time in total.

The data were processed using content analysis, which proceeded from first identifying the salient features of each interview section in the script (for a complete script, see REKK 2008), which then served as criteria for the evaluation of each interviewer. Once the features had been found, research proceeded to trace their presence or absence in each interview. This was followed by juxtaposition of the two gender groups to discover the group properties. Changes to the script also served as a subject to content analysis. 


\section{Content analysis and results}

The section presents the findings of the current study along with some preliminary interpretation. As the number of participants is fairly small, the results are given in raw figures and not in percentage.

\subsection{Introduction}

Analysing the representation of the salient features in the introduction (Table 1) we can see that in 17 interviews out of 18 , the introductory stage is present.

Table 1. Interview introduction element representation in interviews

\begin{tabular}{|l|l|c|c|}
\hline \multirow{2}{*}{ No. } & \multicolumn{1}{|c|}{ Element } & \multicolumn{2}{c|}{ Present/missing in interviews } \\
\cline { 3 - 4 } & & Men & Women \\
\hline 1. & Candidate number/code & $7 / 2$ & $9 / 0$ \\
\hline 2. & Greeting the candidate & $4 / 5$ & $5 / 4$ \\
\hline 3. & Introducing the interviewer & $6 / 3$ & $6 / 3$ \\
\hline 4. & Introducing the assessor & $6 / 3$ & $6 / 3$ \\
\hline 5. & Enquiring about well-being & $9 / 0$ & $7 / 2$ \\
\hline 6. & Asking warm-up questions & $8 / 1$ & $9 / 0$ \\
\hline
\end{tabular}

All women start with the warm-up stage, but with male interviewers, a discernable introductory stage is present in eight. In M6, the interviewer does not introduce himself or the assessor; or indeed ask any of the prescribed warm-up questions. Instead, he asks one question which seems to be based on prior knowledge of the candidate's habits.

Candidate's examination code is not skipped by any interviewer. There are, however, differences in the point at which the number is stated: M7 notes it at the beginning of task 1, M9 states it after the candidate has been asked to choose task 1 topic, i.e. half way through the explanation of task 1. Overall, female interviewers were more disciplined here.

Greeting the candidate divides the interviewers into two almost equal groups, those who greet the candidate at the start of the recorded interview (M1, M2, M4, M6, F2, F4, F6, F7, F9), and the rest do not. The behaviour of male and female interviewers does not differ in this aspect.

The interviewers must introduce themselves at the beginning of the exam. Six male interviewers (M1, M2, M5, M7, M8, M9) do so, M3, M4 and M6 do not. The number of female interviewers in this group is also six (F1, F4, F5, F6, F7, F9). The reason is probably because candidates and interviewers are already familiar with each other as teachers and students, thus introductions seem nugatory.

The interviewer has to ask the candidates how they are feeling, helping to relieve examination-related anxiety. All the men do so and respond appropriately; M2, M4, and $\mathrm{M} 7$ follow the script verbatim. M1 rephrases the question and M6 asks 'Are you nervous?', suggesting nervousness rather than deflating it, and follows it up with a seemingly inappropriate question ('Did you jog in the morning?'). Seven women 
enquire about the candidate's well-being: F2, F3, F5, and F6 verbatim. The script expression is expanded in F1, F7 and F9. F4 and F8 skip this part and move straight to warm-up questions. In this section, men adhere to the script more than women.

The focal points of the interview introduction are four warm-up questions, which have the function of leading the candidate into the interview mode. The questions are easy, general interest questions that are set below the test's general B2 proficiency level. They are designed to relieve the candidate's anxiety and increase their confidence (cf. Alas, Liiv 2009). The questions were asked by all but one interviewer: M6 skips the warm-up completely. Fourteen interviewers confine themselves to the script without developing candidate responses, however, F1, F4, and F9 add questions here.

Different types of deviant behaviour are noted. Men are more likely to leave out questions, e.g. M7 only asks one of four warm-up questions. As a result, his introductory phase only lasts 46 seconds, which is over a minute less than the two minutes to which the candidate is entitled.

On one occasion (F1), the interviewer asks all the warm-up questions at once and lets the student decide which question to answer, then adds an additional question. F4 also asks additional questions and when the candidate does not answer in the expected manner, she guides the student in the appropriate direction by asking for clarification. F9 changes the questions to accommodate the student who seems reluctant to respond to the script questions.

The end of the introduction should be signalled by the discourse marker 'Thank you'. Five men (M1, M4, M5, M8, M9) end this stage properly. M2 ends with 'okay', M3 and M7 with 'alright' and in M6 the introductory stage is not present. The introduction is appropriately finished by six female interviewers (F1, F3, F4, F5, F6, F9). F2 and F7 ended the introduction with 'okay' and F8 does not use words at all, signalling the end with a back-channelling sound 'mhmh'.

The maximum length of the stage with men is 1 minute 22 seconds and the minimum is 28 seconds. The mean duration is 1 minute 1second, brought down by M6 skipping the warm-up phase. The maximum length of this stage with female interviewers is 1 minute 44 seconds and the minimum is 54 seconds. The mean time spent is 1 minute14 seconds. The longer mean length can be attributed to female interviewers asking the warm-up questions, and occasionally adding supplementary questions (F1, F4, F9). It should be noted that the interviewers in general could have made more of the 2 minutes allotted to the introduction, as the mean as well as the individual introduction lengths fall considerably short of the given time. Clear gender differences are present in the minimum and maximum length of the interviews, as well as the mean length. All women spend more time with each candidate than men, they allow more speaking time for the candidate, appearing to be more accommodative conversation partners than men.

\subsection{Task 1. Monologue and follow-up questions}

In task 1, the script has been developed to provide maximum support for the candidate and must be quoted verbatim to ensure uniform treatment of candidates. The criteria selected to analyse the transition to task 1 , as well as their representation in the interviews are summarised in the Table 2 below. 
Table 2. Element representation in task 1

\begin{tabular}{|l|l|c|c|}
\hline \multirow{2}{*}{ No. } & \multicolumn{1}{|c|}{ Element } & \multicolumn{2}{c|}{ Present/missing in interviews interviews } \\
\cline { 3 - 4 } & & \multicolumn{1}{c|}{ Men } & Women \\
\hline 1. & Essence of task & $8 / 1$ & $8 / 1$ \\
\hline 2. & Expected monologue length & $9 / 0$ & $8 / 1$ \\
\hline 3. & Option to take notes & $8 / 1$ & $8 / 1$ \\
\hline 4. & Comprehension & $4 / 4$ & $4 / 4$ \\
\hline 5. & Providing pen and paper & $7 / 2$ & $8 / 1$ \\
\hline 6. & Requesting topic selection & $9 / 0$ & $9 / 0$ \\
\hline 7. & Asking for the topic number & $9 / 0$ & $8 / 1$ \\
\hline 8. & Signalling start of preparation time & $7 / 2$ & $9 / 0$ \\
\hline 9. & Signalling end of preparation time & $8 / 1$ & $9 / 0$ \\
\hline 10. & Allowing time for monologue & $9 / 0$ & $9 / 0$ \\
\hline 11. & All follow-up questions & $8 / 1$ & $9 / 0$ \\
\hline 12. & Signalling end of task 1 & $9 / 0$ & $9 / 0$ \\
\hline
\end{tabular}

Previous research on the topic (Alas 2010) prompted the current research to consider also maintaining the order of the script elements; adhering to the wording of the lead-in information; supplementary information the interviewers include in the instructions to the candidate during the lead-in to task 1.

As can be seen, the elements feature in the interviews to varying degrees. Only three are present in all: topic selection, allowing time for delivering the monologue, signalling the end of the task.

\subsubsection{Essence of the task}

In general, the interviewers seem to recognise the need to explain the task. Sixteen interviewers explain it, although M6's lead-in is limited to: 'You have preparation time for the monologue', and the interviewer F9 is almost as laconic, adding only the length of the preparation time '[---] you have three minutes to prepare for the monologue [---]'. In those interviews, however, the candidate is not swayed by the minimum information provided and proceeds to prepare appropriately, which testifies to adequate examination preparation and familiarity with the procedural demands. It could prove to be a problem with candidates who are less prepared, i.e., do not know what the essence of the task is or how long they should be prepared to talk. If deprived of that information, they would be disadvantaged compared to others who get it. Hence, the validity is at stake. There are no discernable genderrelated behavioural differences here, however.

\subsubsection{The expected length of the monologue}

Before the candidates start thinking about what to say, they must be reminded of the expected speaking time. All but one interviewer state the expected length: F9 gives the information only after the preparation time has ended. It is interesting 
that she deems it more appropriate to shift it closer to the actual presentation of the monologue. However, as it is more important to know the speaking time when starting to plan the monologue, shifting the information may affect validity.

\subsubsection{Length of the uninterrupted preparation time}

For task 1, the candidate should have 3 minutes of uninterrupted preparation time. The candidates have the right to forgo this if they wish. Figure 1 below illustrates the amount of time men and women allowed for monologue preparation, the y-axis representing the time (minutes/seconds) and the $\mathrm{x}$-axis the participants.

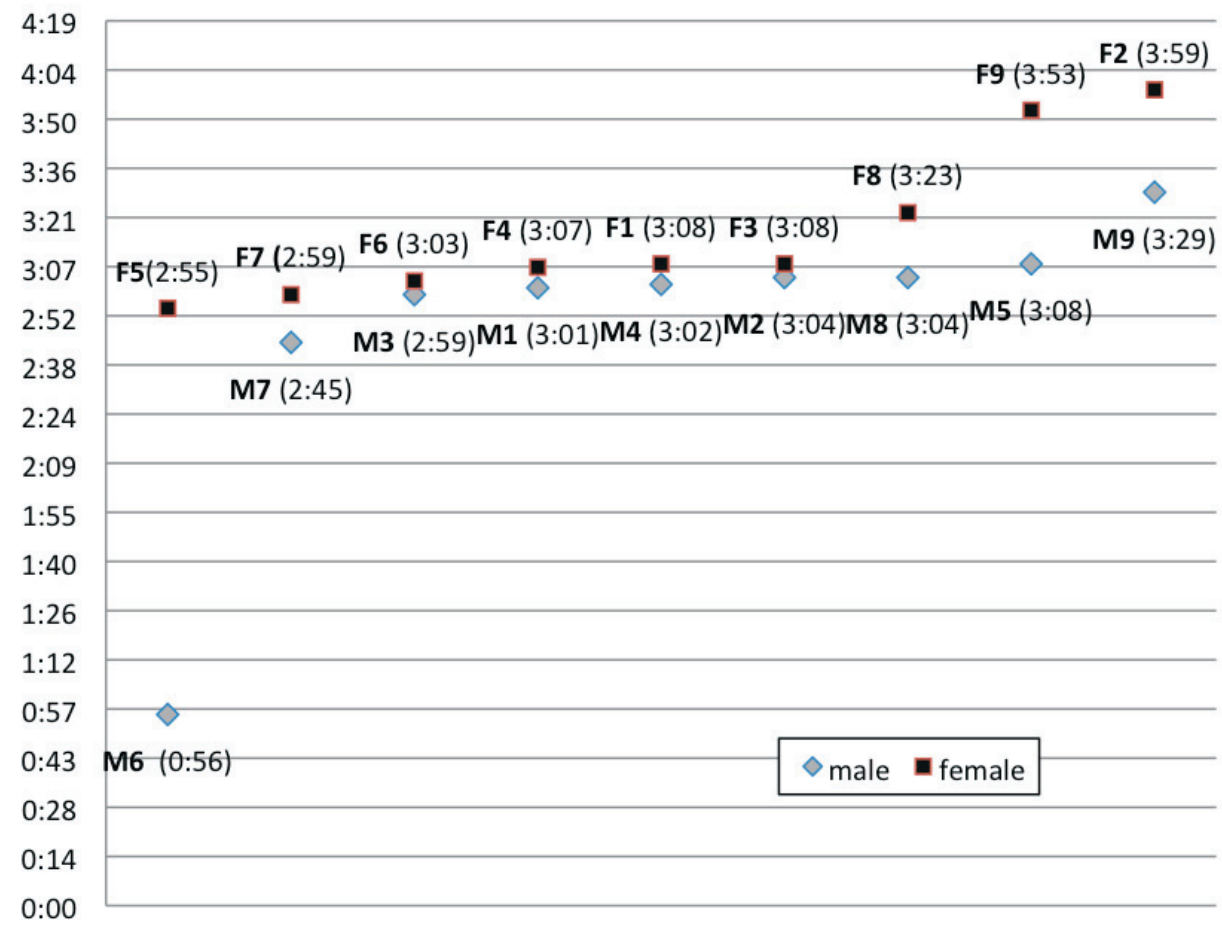

Figure 1. Monologue preparation time with male/female interviewers

In M6 and M7, the candidate wished to begin the monologue sooner and this was granted. Both of these cases were excluded from the calculation of the mean time in the male group. The mean is 3 minutes 6 seconds; the longest time allowed is 3 minutes 29 seconds, and the shortest 2 minutes 59 seconds. With the exception of M5 and M9, most male interviewers come close to the time required (+/ 4 seconds), varying marginally. A notable exception is M9 who allows nearly half a minute more than others, giving his student a clear advantage.

A cursory look at Figure 1 above indicates that women allow their candidates more preparation time. Also, considerably more fluctuation in the amount of time allowed is observed. The mean time is 3 minutes 17 seconds, i.e. most female interviewers (F1, F2, F3, F4, F6, F8, F9) allow the candidates more than 3 minutes, F5 and $\mathrm{F} 7$ fall marginally under the specified time. Compared with male interviewers, a difference is evident in the maximum length of preparation time: 3 minutes 59 seconds (F2). This is nearly a minute longer than envisaged. Almost the same can be observed with F9 (53 extra seconds). Both of these candidates have nearly 25\% 
more time to prepare for the task than their peers. There is a clear gender-related difference here: women are more lenient than men when keeping time. There is, however, great variation also within the groups.

\subsubsection{Note-taking}

During preparation for task 1, students should have pen and paper at hand for taking notes. It is the interviewer's responsibility to make them aware of that.

With the exception of one female (F9) and one male interviewer (M7), all the interviewers conform to this requirement. The script is followed verbatim by four men (M1, M2, M3, M8) and four women (F1, F3, F5, F6). In M4, M5, F4, and F8, 'and' is inserted at the beginning. Other script deviations include paraphrasing, for instance, F7 tells the candidate: 'And yeah, feel free to take notes [---]', and M7 only implies that the candidate can take notes without telling the candidate clearly: 'Here's a pen ... here's some paper if you need it'. All in all, there is a marginal disadvantage to the candidates with male interviewers.

\subsubsection{Enquiring about comprehension}

Asking if the candidate has understood the instructions should give the interviewer feedback about whether the candidate is ready to start monologue preparation. Compared with other elements this phase seems to be considered less important and is omitted by five male and five female interviewers: M1, M2, M3, M8, F1, F2, F5, F6 ask the question. It may be worthwhile to note that whenever the question is asked, the response is always positive. As the instructions are given in simple language and there might be accompanying body-language (nodding) on the part of the candidate, the interviewers might consider the query irrelevant.

\subsubsection{Providing pen and paper}

Offering pen and paper for notes was less widespread among men than women. M1 uses the script verbatim. M2 seems unsure of what he needs to say: 'Alright, here's ... aaa ... you have a pencil and have some paper.' In M3, the word 'pencil' is replaced with 'pen'. M5 paraphrases the instruction: 'And you can use this paper as rough notes paper.' M6 tells the candidate he can take notes, but pen and paper is not mentioned. M7 says, 'Here's a pen ... here's some paper if you need it.' In M8, the interviewer's comment on pen and paper seems to indicate that the candidate is expected to move somewhere for the preparation stage: 'So, here's a pen and you'll find some paper there.' M9 mentions the option to take notes but does not state that there is pen and paper available.

Eight women provide pen and paper; however, only F3 and F6 use the script verbatim. F1, F2 and F5 add a connector. F2 and F9 make an insignificant word order change. In $\mathrm{F}_{4}$, the candidate is made aware of the possibility of taking notes but providing pen and paper is implied not stated: 'And you can make some notes if you wish'. F7 tells the candidate, 'There's pen and paper over there', which also 
indicates that the candidate is expected to move to another seat. F8 seems to remember the need for paper and pen somewhat later, as she remarks: 'Oh yes, and a pen and some paper'.

Overall, the option of using pencil and paper is made known to the candidate, but the interviewers do not give the instruction in a consistent way. The gender distinction is slightly to the disadvantage of men, as they refrain from giving the option more often than women.

\subsubsection{Requesting selection of a topic}

Topic selection is one of the three elements present in all interviews, but the wording varies widely. Only two men (M1, M3) use the script verbatim, all others change the tone of the request. In the M2 interview, the candidate is told: 'And you can take one of the topics over there'. M4 softens the request by saying: 'And would you please pick a topic'. M5 reduces the level of politeness by using the imperative: 'Choose a topic'. M6 utters, 'And please start with the topic', which is ambiguous and can be interpreted both as a request to choose as well as to start speaking on it. M7 seems unsure of what he needs to say, his remark, 'Alright, now ... I'd ... like ... you ... to pick ... a topic' may be a sign that he is not familiar with the script. Both M8 ('But before this would you please choose one of the cards in front of you'), and M9 ('I would like you to take a ticket to choose a topic') use an alternative wording. Here, synonyms have been introduced for the 'topic' - card and ticket - which is unnecessary and linguistically inappropriate. Also, the alternative wording suggested is unnecessarily long.

Women adhere more to the prescribed script - F1, F4, F5, F6, and F9 use the script verbatim. F2 asks the candidate to 'Please, pick up a topic', indicating a slight struggle with the language. F7 extends the script: 'Please, pick a topic for yourself . Both F3 and F8 unnecessarily use the synonym 'card' for 'topic'.

\subsubsection{Asking for the topic number}

As it is important for the interviewer and the examiner to know which monologue topic the candidate will be speaking on, which set of follow-up questions to ask, and which role-play should ensue, asking for the topic number is critical.

All but one interviewer ( $\mathrm{F} 4)$ ask for the number although there are differences in wording. Slight changes involve either leaving out the word 'topic' (M2, M9) or replacing it by a pronoun (e.g. M4 'What's the number of it?'). M8 asks the candidate, 'What is the number of the card?', maintaining the synonym he had introduced earlier, and M3, by using 'Tell us the number of your topic', increases the level of directness of the interchange. The most notable change is present M6, who orders the candidate to 'Tell us the topic', completely changing the nature of the request: instead of the number of the topic the candidate is ordered to give the name of the topic, which is confusing as there are usually at least two sub-topics identified by the number under one general topic.

Three women (F1, F5, F6) quote the script, in others the wording is changed. F2 asks the candidate to 'Tell me the number'; F8 'Could you tell us the number?'. 
Similarly, F9 asks 'What is the number?'; in F7, 'Could you tell us the number as well?'; and in F3, the interviewer says 'What is the number of the card?'. As can be seen, most interviewers include the element in the script, but communicate the message of the request rather than deliver it precisely. The number of women who did that exceeded that of men.

\subsubsection{Signalling beginning of preparation time}

The script phrase 'Now you will have 3 minutes.' serves both as a signal to the candidate to start topic preparation and the point for the interviewer for time-keeping. Three men quote the script exactly (M1, M2, M3). M4 and M5 add connectors to enhance cohesion; the latter also mentions the purpose of the given time similarly to M9 ('to make notes and to prepare for the task'), M8 adds a comment about who ends the preparation time ('Okay, so I will tell you then the three minutes are up'). M6 and M7 omit the phase altogether, which makes keeping time problematic.

Three women quote the script verbatim in (F1, F3, F5). F2 changes the tense, F4 alters the tone and the word order ('So, remember you have now 3 minutes'). F6 uses a different connector ('So, you will have 3 minutes'). F7, F8 and F9 clarify the purpose of the time given ('So, now you will have 3 minutes to prepare').

Although the amount of participants who follow the script verbatim in both groups is the same, and the changes introduced by the interviewers have very similar patterns, the data suggest that women try to follow the script more conscientiously, since none of them omit the phase as is the case with some male interviewers.

\subsubsection{Transition from preparation to monologue delivery}

The transition from the preparation phase to monologue delivery can be initiated by either the candidate or the interviewer. When the three minutes are up, the interviewer must instruct the candidate to start speaking, but if the candidates wish to forgo using all or some of the preparation time, they can. Regardless who stops the preparation, the interviewer should remind the candidate of the expected length of the monologue and signal the beginning of the speaking.

In the oral proficiency interviews analysed, two candidates ask to begin before the end of the allotted time (M6, M7). The two interviewers respond by diametrically different strategies: M7 follows the prescribed script verbatim, whereas M6 skips the reminder and allows the candidate to proceed by saying 'Good, take a seat'. The comment is significant in that it seems to imply a procedural discrepancy noticed earlier whereby the candidate is required to move about in the examination room preparing at one desk and responding at another. This may be an attempt to provide space for the candidate during the preparation time, but with so little time for the interview, moving between tables seems to cause unnecessary confusion and waste of interview time.

The transition script is followed verbatim by M3 and M7. M1 adds a more pronounced ending signal, 'Time is up' ('Alright. Time is up. Remember, you have 2 minutes for speaking. I will tell you when the time is up.'). M2 and M5 change the connector, starting with 'right' / 'okay' respectively. Information is left out on 
three occasions: M4 leaves out the phrase 'Please start speaking now', making the beginning of the candidate's turn ambiguous, and M8 and M9 skip 'alright' - the signal to stop preparation.

Similar patterns occur with women. The script is followed verbatim in F1, F2 and F8. F3 and F9 use a longer phrase to stop preparation ('Alright, the time is up', 'Alright, I have to interrupt you now'). F3 changes the modality of the wording, implying that the candidate has to speak for two minutes, whereas there is no such obligation. Two minutes is just the time available to the candidate. ('And remember you have to speak for 2 minutes. I'll tell you when the time is up.'). Similarly to F5, there is no signal to start the monologue. In F4, 'alright' is left out at the beginning, so the interviewer resorts to no verbal signalling of the end of preparation time. In F6, the candidate is addressed by name; otherwise the instruction is intact. F7 shortens the signal to start speaking ('Alright. Remember you have 2 minutes for speaking, yeah. [---] So, please start.').

Once again, women adhere to the script more rigorously, but both groups need more awareness with regard to the functions of the different elements of the script.

\subsubsection{Follow-up questions}

After the monologue has been completed, four scripted follow-up questions should ensue. The interviewers should not alter the questions or leave any of them out unless the candidate has already responded to them in the monologue.

Seven men handle the questions appropriately. M1 asks a question although the candidate has already covered it in the monologue, whereas M6 leaves out a question although the student has not addressed it. Asking a question that has already been answered may confuse the candidates as they might think the answer was erroneous either from the point of view of content or language. Leaving questions out may deprive the students of the chance displaying the full spectrum of their language proficiency. It also makes it problematic to elicit a rateable sample from the candidate. Both behaviours undermine test validity.

Women appear more consistent than men, as they do not change the order of the questions or leave any of them out. Some interviewers, however, add information, paraphrase or ask additional questions (F3, F4). This seems to be done in an attempt to assist the candidates when they fail to respond, and can thus be perceived as an accommodating behaviour. F3, for example, offers additional information in the form of a clarifying comment to the candidate. In addition to the above, $\mathrm{F} 4$ resorted to evaluative comments ( $\mathrm{mhmh}$ with a rising intonation, good), which, in addition to being a characteristic of teacher talk rather than ordinary interaction, may potentially mislead the candidate as to the quality of their performance. Both behaviours are detrimental to OPI validity. The above behaviours are not present in any of the interviews conducted by men. 


\subsubsection{Signalling the end of task 1}

Most men (M1, M2, M3, M4, M8, M9) end this stage appropriately. M5 does not thank the candidate but informs her that they are moving to task 2, reducing the politeness level. M6 paraphrases the script, making the instructions more specific ('Thanks! [---] Let's move to the role (.5) play'). M7 adds a connector and extends the thank-you ('Right, thank you very much. Let's move on to the next task.').

Female interviewers mostly follow the script; six use it verbatim (F1, F2, F5, F6, F8, F9). F3, F4 and F7 insert additional connectors or deictic expressions for the sake of cohesion ('Alright, thank you. And let's move on to the next task', 'So, thank you. Now, let's now move to the next task', 'Thank you. Let's move on to the next task then.').

\subsubsection{Monologue length}

The designated monologue time is two minutes. If the monologue is shorter, the interviewer should prompt the candidate to continue to obtain a rateable sample. As can be seen in Figure 2 below there is a notable difference in the monologue length in the two gender groups.

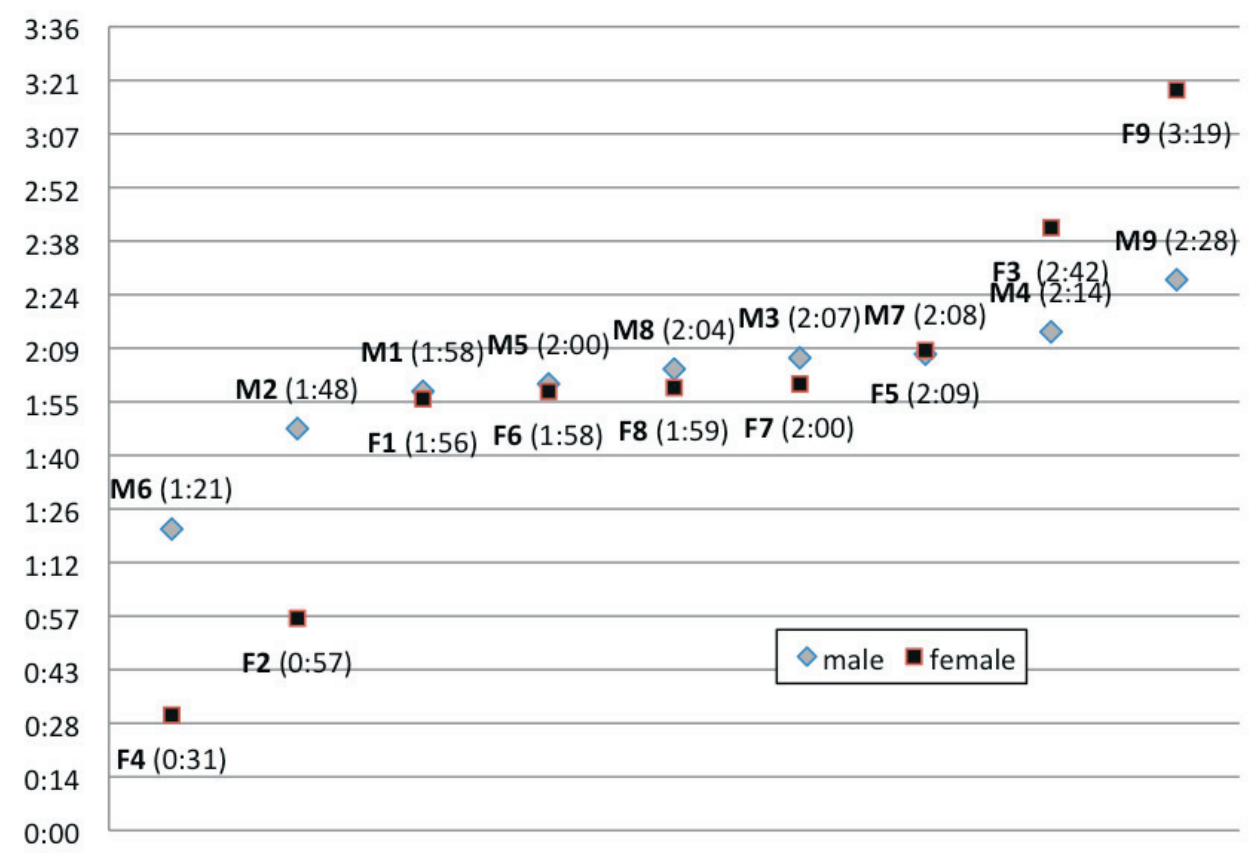

Figure 2. Monologue length with male/female interviewers

The monologue length is under two minutes in three male interviews (M1, M2, M6). The longest time is 2 minutes 28 seconds (M9) and the shortest 1 minute 21 seconds (M6). Two interviewers prompt the student to continue (M2 and M9). In M9, the interviewer does that unnecessarily as a sample of two minutes has already been elicited. M6, however, should have prompted the candidate to proceed, as the monologue here was more than $25 \%$ shorter than expected.

The candidate speaks for less than two minutes in F1, F2, F4, F6 and F8. The longest monologue is 3 minutes 19 seconds (F9) and the shortest 31 seconds (F4). 
Three interviewers prompt students to continue (F2, F4, F9): in F2 and F4 this is justified, as the length falls considerably short of the expectation, whereas in F9 the monologue had already lasted over three minutes, so prompting to continue indicates difficulty in managing time.

Eliciting a rateable sample is achieved admirably by most interviewers but examples of deviant behaviour even in a small sample like ours seems to imply that there is a need to address the issue in interviewer training. The current dataset seems to indicate, however, that time-keeping practices do not depend on interviewer gender but rather individual interviewer idiosyncrasies.

\subsection{Task 2. Role-play}

The role-play poses the added challenge of performing a dual role for the interviewers: they need to adhere to the script's procedural requirements as well as assume the role dictated by the role-play cue card and actively participate in communication. Both roles presuppose different behaviour: as the person managing the interview, their linguistic contribution is restricted by the script. As a role-play participant, they are expected to take the cue from the candidate and therefore modify their responses according to the candidate's input.

The script criteria for the role-play and their representation in the interviews can be seen in Table 3 below.

Table 3. Element representation in task 2

\begin{tabular}{|l|l|c|c|}
\hline \multirow{2}{*}{ No. } & \multicolumn{1}{|c|}{ Element } & \multicolumn{2}{c|}{ Present/missing in interviews } \\
\cline { 3 - 4 } & & Men & Women \\
\hline 1. & Appropriate lead-in to task 2 & $9 / 0$ & $9 / 0$ \\
\hline 2. & Note preparation time & $9 / 0$ & $9 / 0$ \\
\hline 3. & Keeping time & $9 / 0$ & $9 / 0$ \\
\hline 4. & Prompt start of the role-play & $8 / 1$ & $8 / 1$ \\
\hline 5. & Participating in role-play & $9 / 0$ & $9 / 0$ \\
\hline 6. & Stating end of interview & $9 / 0$ & $8 / 1$ \\
\hline
\end{tabular}

\subsubsection{Lead-in to task 2}

All men include the lead-in in their interviews: M1 and M8 follow the script verbatim. Others introduce minor additions: M2, M3 and M4 combine sentences with a conjunction; M5 makes the instructions more specific ('And you have $\mathrm{mm}$ one minute to think about it and I'll tell you when the time is up, when you should start your role-play.'); M6 additionally mentions the absence of the right to take notes at this stage. M7 increases the politeness level by adding, 'would you' at the beginning. M9 gives some information (time) twice and adds a comment about note-taking ('Please read it to yourself and you have one minute to think about it, I'll tell you when the time is up and notes ... note taking is not allowed in this stage. You have one minute.'). 
Lead-in was also present in all female-led interviews. F4 and F6 quote the script exactly. F1, F2 and F5 add conjunctions and and so to connect different parts. F3 is struggling to locate necessary role-play materials. Once she finds them, she offers more specific information ('I must find a card for you. Is it A5? So, this is your role-play card. Please have a look at it. You have one minute for it. And when the time is up, I'll tell you.'). F7 engages all the parts of the lead-in but uses connectors to link the parts of the section. There are additional comments about note-taking and an apology to finish. ('So, here is your card. Please read it to yourself. Yeah, I'll take that one. And you have one minute to think about it and I will tell you when the time is up. You cannot take any notes. Sorry.') The instructions are more specific and elaborate in F8, where the interviewer is paraphrasing most instructions ('The next task is role play. And I'll give you a card. You have on minute in order to familiarise yourself with the content of this card and I will tell you when the time is up and you should start.'). The same happens in F9, with an additional remark about the beginning of the role-play ('and then we start the role-play'). Overall, women are more accommodating, adding supplementary information in this stage.

\subsubsection{Noting the length of the preparation time}

The interviewer must remind the candidate of the one-minute time limit for roleplay. Five men use the script verbatim (M1, M2, M4, M5, M8). M3 starts the instruction in a similar manner to that of the introduction to task 1, but then reverts to the appropriate script. M6 adds a comment about taking notes, which is not in script. M7 and M9 insert a connector. In six female-led interviews (F1, F2, F4, F5, F6, F7), the interviewer uses the script verbatim. F7 adds a connector to the beginning of the sentence, similarly with $\mathrm{M} 7$ and M9. F3 and F8 resort to paraphrase and by doing so, may mislead the candidate. F3 uses a prepositional phrase 'for it' instead of 'to think about it'. In doing so, she is misleading the candidate to think that the minute is meant for reading the task situation, whereas the minute is intended to think about task completion. F8 paraphrases the given instruction as above and inadvertently ends up giving the candidate false information similar to F3 ('You have one minute in order to familiarise yourself with the content of this card.'). Overall, the preparation time is mentioned by all interviewers and although there are more women who follow the script to the letter, the changes to instructions do not lead to ambiguity in interviews led by men, whereas in the female counterparts they do.

\subsubsection{Length of role-play preparation time}

The time allowed by male and female interviewers for role-play preparation, presented in Figure 3 below, shows different patterns of time management in the respective gender groups.

Overall, men manage to adhere to the one-minute time-slot. The shortest role-play preparation time allowed is 48 seconds $\left(\mathrm{M}_{7}\right)$, and the longest 1 minute 7 seconds (M5). More training should focus on precise time-keeping, ensuring similar conditions for all candidates. 


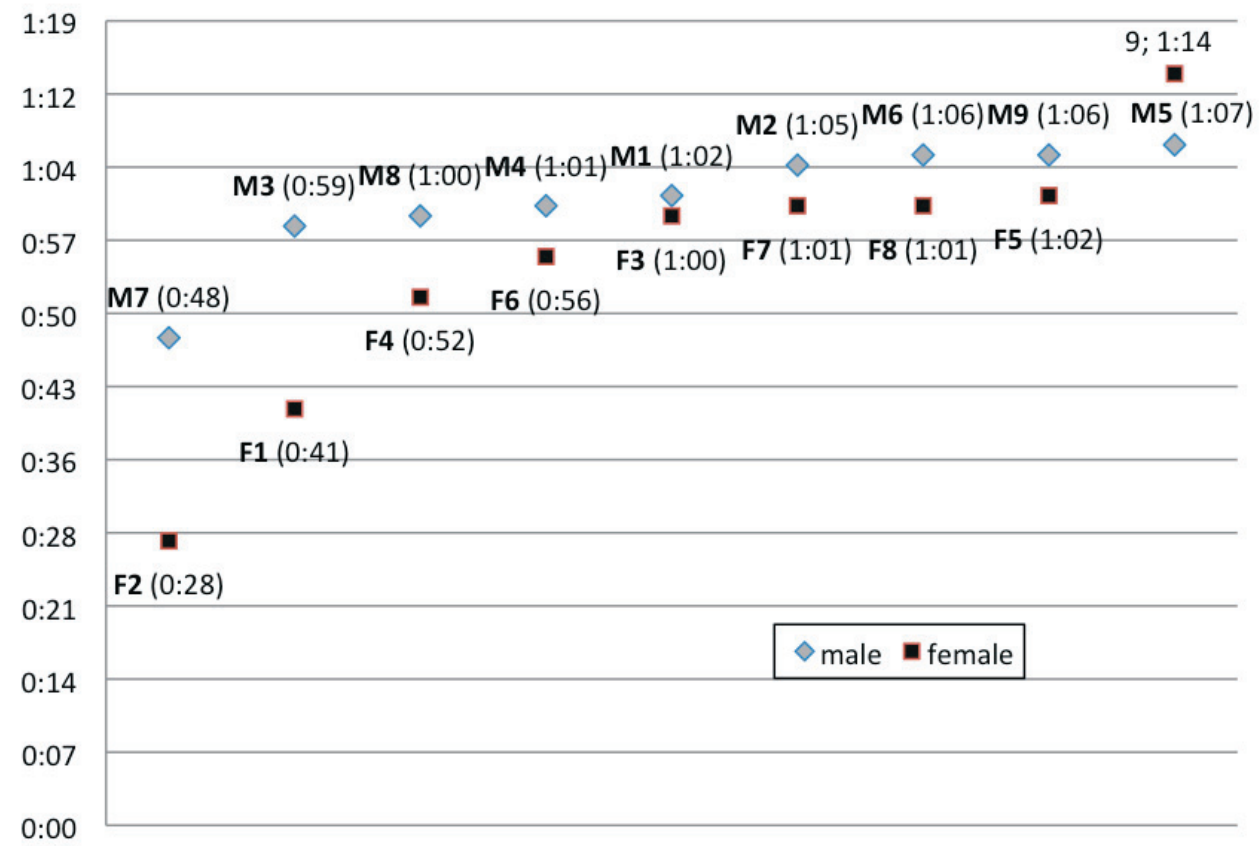

Figure 3. Length of role-play preparation time with male/female interviewers

Women's results show more variation. In F2 the time is noticeably shorter because the candidate initiates the role-play after 28 seconds of thinking. The most time allowed is 1 minute 14 seconds in F9, and the shortest time is 41 seconds (F1). Generally, women are more precise time-keepers (F3, F5, F6, F7, F8), their timing is closer to the one-minute limit than that of men.

\subsubsection{Prompting start of role-play}

Provided that the candidate has not initiated task 2, the interviewer must prompt the beginning of the role-play once one minute has elapsed. In the analysed interviews, the candidate starts the role-play earlier on two occasions (F2, M7). In male-conducted interviews, the script is followed exactly on five occasions (M2, M4, M6, M7, M8, M9). In interviews M1, M3, and M5 the instruction is modified: M1 adds an initial discourse marker 'alright' ('Alright, could you start now?'); M3 increases the politeness level by adding 'please' at the end. M5 supplies a connector at the beginning and drops the modifier 'now' at the end ('So, could you start the role play?'). Three women follow the script verbatim (F3, F5, F6). F1 shortens instruction ('Could you start now?'), and F7 adds 'okay' to the beginning. F4 grants the candidate permission to start speaking ('You may start') thus changing modality. F8 uses the imperative ('I think you should start now'), and F9 used the phrase 'Can we start?' leaving it ambiguous who the initiator of the interaction should be. Thus, in the current script section, women are more direct, and at times less polite than male interviewers. 


\subsubsection{Role-play participation}

Role-play is handled with mixed success. On the one hand, the interviewers actively participate in it and answer the candidate's queries according to the script. The problem is the interviewers' unwillingness to adapt their answers to the candidates' questions. Interviewers' cue cards for the role-play contain plausible answers to candidates' questions. As it is difficult to predict what form the candidate questions are going to take, the interviewer cue card answers are usually more detailed than necessary. The interviewers have been instructed to adapt cue card answers to particular questions. Interestingly, it transpires that the interviewers do not know if they can modify the lengthy answers or not. Thus unnecessarily long answers can be found in the recordings to questions requiring a short answer. Another reason for not modifying the response might be the interviewers' mistrust of their own language proficiency. It is safe to read out the long answer: some part of it will definitely answer the candidate's question and it is also linguistically correct.

The entire answer is read out in six role-plays by male interviewers (M1, M2, $\mathrm{M}_{3}, \mathrm{M}_{4}, \mathrm{M} 8, \mathrm{M} 9$ ), M5, M6 and M7 adapted the answer to the respective question. Women respond more appropriately. In fact the result is reversed compared to men: F1, F2 and F8 read out the entire answer, all others adapt their answers.

\subsubsection{Signalling end of interview}

The interviewer should say to the candidate clearly that the OPI has been completed, after which the recorder is switched off. Other procedural comments about signing the attendance form or learning about interview results should not be part of the recording.

Six men follow the script exactly (M1, M2, M3, M4, M5, M7). In the three remaining recordings, procedural comments are included too: M6 asks the candidate to sign his name and M8 and M9 inform the candidate about getting the results. Five women quote the script (F1, F2, F3, F4, F5). F6 switches off the recorder before announcing the end. F7 and F9 add a connector at the beginning and F8 supplements the closing remark by an explanation ('This is the end of the interview and the end of the examination.').

\section{Discussion and implications}

The hypothesis of the current study was that the interviewer conduct in oral proficiency interviews during the national examination in the English language in Estonia will display gender-related differences, and perhaps reveal identifiable patterns. Content analysis revealed that none of the interviewers completely followed the script. Deviations from the script ranged from leaving out entire sections (i.e. introduction to the interview) to introducing additional discourse markers (e.g. connectors; and, but, ok) to achieve cohesion. In some cases, both men and women added supplementary information to be more specific (e.g. substituting the general word 'task' with the specific 'role-play'), and gave the candidate more information than provided by the script (e.g. forbidding note-taking in task 2). We may argue 
that while some of these changes are unimportant and should not affect the validity of the OPI (e.g. adding connectors) there are deviations, such as leaving out entire sections of instructions or changing the sequence of information, which alter the amount of support the student is getting during his/her performance and that may certainly influence the outcome.

Both men and women used accommodative strategies to help the candidate, e.g. they slowed down their speech when asked for repetition. However, women also asked additional questions to direct the candidates if they seemed to have difficulties with the task. This is not an acceptable accommodation technique and may affect validity, as some candidates have an advantage with more information/support. Women seemed to have more difficulty in separating their role as a compassionate language teacher from that of a friendly but neutral OPI interviewer.

Time-keeping during the OPI was, in general, a problematic area, as at least half of the interviewers of both genders were imprecise. There were some alarming cases where the interviewer allowed a significant amount of extra time for both task preparation and task delivery. As this occurred with both male and female interviewers, gender cannot be claimed to be a distinguishing feature. Overall, it seemed, however, that women were more lenient than men, and allowed for more speaking time. Here, again, it should be mentioned that this might have contaminated examination validity since all the candidates were not treated equally.

Women seemed to adhere more to the script demands than men, as the necessary interview elements were present more often. But both men and women changed the sequence of information, e.g. not all men stated the candidate's code number at the beginning of the interview and some women asked the candidate to pick a topic for the monologue before explaining the essence of the task. However, if we take into consideration the fact that female interviewers attempted to help the candidate to perform better by providing more direction and men seemed more likely to omit questions/phases, both gender groups are undermining the validity of the OPI in different ways. It is difficult to state which of the interviewers' behaviour is more detrimental. This could be a direction for further research.

With interviewer training, the differences in behaviour with regard to the characteristics pointed out in this research can and should be minimised. To ensure the validity of the OPI, more training seminars should be conducted, as it is evident that not all interviewers seem to acknowledge the necessity of adhering to the script requirements as a strategy for maintaining OPI validity. Recording of OPIs should be obligatory for all the candidates as an additional tool for the standardisation of interviewer behaviour. Recording the OPI would perhaps motivate the interviewers to be more consistent in their behaviour. Given, however, that the current study was conducted relying on recorded interviews, recording alone does not solve the standardisation problem.

\section{Conclusion}

The current study is the first of its kind to attempt a comparison of the behaviour of male and female interviewers in the context of the oral proficiency interviews of the national examination in the English language in Estonia. The content analysis of the 18 interviews involved confirmed the hypothesis to some extent: there was 
an overall attempt to follow the interviewer script in broad terms by both gender groups, but women tended to be more accommodative interview partners and more generous with time. Male interviewers seemed to be more direct in their interaction and also more likely to adhere to the general script demands rather than following it to the letter. Whether the differences in the behaviour can really be attributed to gender, or are the result of insufficient training or awareness of the interviewer role is still inconclusive at this point. More definitive conclusions about gender-related interviewer effects on the OPI would require the analysis of a larger number of interviews. While doing so, research could also make use of more advanced data mining and processing software for more substantiated conclusions.

\section{References}

Alas, Ene 2010. The English Language National Examination Validity Defined by Its Oral Proficiency Interview Interlocutor Behaviour. Tallinn University Dissertations on Humanities 22. Tallinn: Tallinn University Press.

Alas, Ene; Liiv, Suliko 2009. Constraints of measuring language proficiency in Estonia: The national examination in the English language. - Eesti Rakenduslingvistika Ühingu aastaraamat, 5 / Estonian Papers in Applied Linguistics, 5, 19-32. http://dx.doi. org/10.5128/ERYa5.02

Brown, Annie 2003. Interviewer variation and the co-construction of speaking proficiency. Language Testing, 20 (1), 1-25. http://dx.doi.org/10.1191/0265532203lt2420a

Lazarton, Anne 1996. Interlocutor support in oral proficiency interviews: The case of CASE. Language Testing, 13 (2), 151-172. http://dx.doi.org/10.1177/026553229601300202

Lazarton, Anne 2002. A Qualitative Approach to the Validation of Oral Language Tests. Studies in Language Testing 14. Cambridge: Cambridge University Press.

Luoma, Sari 2004. Assessing Speaking. Cambridge: Cambridge University Press.

Malvern, David; Richards, Brian 2002. Investigating accommodation in language proficiency interviews using a new measure of lexical diversity. - Language Testing, 19 (1), 85-104. http://dx.doi.org/10.1191/0265532202lt2210a

McNamara, Tim; Lumley, Tom 1997. The effect of interlocutor and assessment mode variables in overseas assessment of speaking skills in occupational settings. - Language Testing, 14 (2), 140-156. http://dx.doi.org/10.1177/026553229701400202

Morton, Janne; Wigglesworth, Gillian; Wiliams, Donna 1997. Approaches to the evaluation of the interviewer performance in oral interaction tests. - G. Brindley, G. Wiggleworth (Eds.). Access: Issues in English Language Test Design and Delivery. Sidney: National Centre for English Language Teaching and Research, 175-196.

O'Loughlin, Kieran 2002 The impact of gender in oral proficiency testing. - Language Testing, 19 (2), 169-192. http://dx.doi.org/10.1191/0265532202lt2260a

Põder, Irma 2011. 2011. aasta inglise keele riigieksami lühianalüüs. Riiklik Eksami- ja Kvalifikatsioonikeskus. www.ekk.edu.ee/120917 (04.03.2012).

REKK 2008 = Inglise keele riigieksam 2008: Introductory stage (sample). Scripts (sample). Riiklik Eksami-ja Kvalifikatsioonikeskus. http://www.ekk.edu.ee/valdkonnad/uldharidusvalishindamine/riigieksamite-materjalid-2008/inglise-keel (04.03.2012).

Ross, Steven 1992. Accommodative questions in oral proficiency interviews. - Language Testing, 9 (2), 173-185. http://dx.doi.org/10.1177/026553229200900205

Ross, Steven; Berwick, Richard 1992. The discourse of accommodation in oral proficiency interviews. - Studies in Second Language Acquisition, 14 (2), 159-176. http://dx.doi. org/10.1017/So272263100010809 


\title{
INTERVJUEERIJA KÄITUMISE ISEÄRASUSED KEELEPÄDEVUSTESTI LABIVIIMISEL: SOOLINE VARIATIVSUS
}

\author{
Edith Reemann, Ene Alas, Suliko Liiv \\ Tallinna Ülikool
}

Artiklis analüüsitakse intervjueerija käitumise soolisi iseärasusi inglise keele riigieksami suulise keelepädevustesti läbiviimisel. Autoreid huvitab, kas on olemas intervjueerija käitumismalle, mis on iseloomulikud ühele või teisele sugupoolele. Samuti vaadeldakse artiklis, kas need käitumismallid võiksid takistada intervjueeritavat oma keelepädevust intervjuu käigus täies mahus demonstreerimast. Uurimuses analüüsitakse üheksat nais- ja üheksat meesintervjueerija poolt läbiviidud suulise keelepädevustesti intervjuud. Tulemused näitavad küll intervjuureeglite üldist järgimist mõlemas grupis, kuid mõlemas grupis ilmneb nii sarnaseid kui ka sooliselt determineeritud erinevusi.

Võtmesõnad: intervjuu, intervjueerija, intervjueeritav, suuline keelepädevustest, valiidsus, sooline variatiivsus

\footnotetext{
Edith Reemann töötab gümnaasiumi inglise keele õpetajana ning on inglise keele riigieksami suulise keelepädevustesti intervjueerija.

edith.reemann@gmail.com
}

Ene Alase (Tallinna Ülikool) teadushuvid on keeletestimine, testide koostamine ja nende kvaliteedi hindamine, õpetajakoolitus, õppekirjanduse hindamine.

ene.alas@tlu.ee

Suliko Liivi (Tallinna Ülikool) uurimisvaldkonnad on kontrastiivuuringud, kultuuridevaheline suhtluspädevus, keelepoliitika, võõrkeelte õpetamise metoodika.

liiv@tlu.ee 